\title{
Genetic risk factors in tumours of the testis: lessons from twin studies
}

\author{
Cornelis B Lambalk ${ }^{1}$ and Dorret I Boomsma ${ }^{2}$ \\ ${ }^{1}$ Division of Reproductive Endocrinology, Research Institute for Endocrinology, Reproduction and Metabolism, \\ Department of Obstetrics/Gynaecology, Academic Hospital, Free University, Amsterdam \\ ${ }^{2}$ Department of Psychonomics, Faculty of Psychology, Free University, Amsterdam, The Netherlands
}

\begin{abstract}
A threefold increase for testicular carcinoma has been reported in male dizygotic twins. In this comment we suggest the hypothesis that over-exposure to endogenously hypersecreted Follicle Stimulating Hormone (FSH) may underlie the pathogenesis. This is supported by several findings. 1) FSH hypersecretion in mothers of dizygotic twins is most likely an autosomal trait implicating the possibility of male offspring with the same hormone characteristic. 2) In testicular carcinoma higher levels of cyclin D2 are found. This is an FSH dependent stimulatory regulator of mitosis. 3) There is a marked similarity between geographical distribution in occurence of dizygotic twinning and testicular carcinoma. 4) Men undergoing surgery for testicular carcinoma have higher FSH concentrations and males with Down syndrome have higher FSH levels and are more at risk to develop testicular carcinoma. We suggest to study FSH secretion in males of familial dizygotic twins and furthermore the risk of developing testicular carcinoma in males with elevated FSH. These men with one testicle and/or with dysfunctioning Sertoli/Leydig cells.
\end{abstract}

Keywords: twinning, testis, neoplasma, follicle stimulating hormone, FSH, genetics, geographical distribution

Males of dizygotic twins are up to three times more at risk for testicular cancer (in particular seminomas) (Odd ratio: 2.8 with 95\% confidence intervals of 1.1-7.0) than males of monozygotic twins. This was one important finding in a study conducted by Swerdlow et al published in the Lancet of 13 December 1997. ${ }^{1}$ They identified twins with testicular cancer diagnosed in England and Wales during 1971-1989. In addition to the risk associated with being a dizygotic twin, men with a twin brother with testicular carcinoma have a greatly increased risk of developing testicular cancer themselves - 75-fold in monozygotic and 38-fold in dizygotic twins. The same study also reports a 35-fold increase in risk of breast cancer in monozygotic twin sisters of young women with breast cancer. Females of dizygotic twins have no increased risk of breast cancer compared to monozygotic twins (Odd Ratio of 1.1 with $95 \%$ confidence limits of $0.8-1.4)$. Young dizygotic sisters (up to 35 years old) of probands with breast cancer had also no increase in risk. In this situation, the risk increased significantly about 5 -fold when over 35 years of age.

Correspondence: Dr Cornelis B Lambalk, Division of Reproductive Endocrinology, Research Institute for Endocrinology, Reproduction and Metabolism, Department of Obstetrics/Gynaecology, Academic Hospital, Free University, PO Box 7057, 1007 MB Amsterdam, The Netherlands. Tel: 003120444 0070; Fax: 00 3120444 0045; E-mail: cb.lambalk@azvu.nl

Received 23 March 1998; accepted 27 May 1998
The study is at least doubly significant: it points to a mechanism for testicular cancer that is associated with dizygotic twinning and it provides strong support for genetic mechanisms involved in the aetiology of testis carcinoma. This is in agreement with an observed 12-fold increased risk of testis carcinoma in non-twin brothers of affected males. ${ }^{2}$ The higher incidence in dizygotic versus monozygotic twins as reported by Swerdlow and colleagues points to a risk factor that is unique to dizygotic twins. In the original publication, an environmental rather than a genetic hypothesis is put forward. Nowadays, overexposure to oestrogenic substances either from the mother or the environment are often mentioned when it comes to male reproductive organ dysfunction. The authors suggest that the increased risk in dizygotic twins is related to intra-uterine exposure to rai sed oestrogen concentrations. However, there is currently no good evidence for such oestrogenic over-exposure during the pregnancy of a dizygotic twin compared to monozygotic twin pregnancies. An alternative would be that the findings point to yet another hereditary endocrine mechanism.

A number of mothers of familial dizygotic twins show hypersecretion by the pituitary of follicle stimulating hormone (FSH). ${ }^{3,4}$ This causes multiple follicle growth, higher levels of oestrogens and multiple ovulation. ${ }^{3,5,6}$ There is no evidence that the trait of having dizygotic twins is inherited in an $\mathrm{x}$-linked manner. ${ }^{7}$ This means that male offspring 
(including twins) of these mothers may carry the involved gene(s). At the moment most evidence points towards the hypothal amus or the pituitary as the primary site of difference in regulation of $\mathrm{FSH}$ secretion between mothers of familial dizygotic twins and controls and that there is no difference in mode of hormonal feedback by the gonads. ${ }^{3}$ This may suggest that male carriers of the gene(s) also hypersecrete FSH.

In males, over-exposure to FSH from puberty onwards is a good candidate for involvement in the aetiology of testis carcinoma. In the first place, testicular carcinoma may be associated with increased FSH action mediated by cyclin D2. Cyclins are proteins that are of importance in the regulation of the mitotic cell division and cyclin D2 messenger RNA is found to be expressed in high amounts in testicular and ovarian tumours. Men undergoing surgery for testicular carcinoma and particularly those that developed a second contralateral germ cell tumour had higher circulating concentrations of $\mathrm{FSH}^{9}{ }^{9}$ Also, there seems to be an increased risk in testicular carcinoma in men with Down syndrome which is a condition that is also associated with increased levels of serum $\mathrm{FSH}^{9}$

Secondly, there is remarkable similarity in geographic distribution of dizygotic twinning and larger testicular volume and the incidence of testis tumours. ${ }^{10,11}$ In Scandinavian populations both the incidence of DZ twinning and of testicular cancer are among the highest in the world. Contrastingly, the incidence of both conditions is lowest in East Asian populations. Moreover, Northern Europeans have larger testes than East Asians. ${ }^{10} \mathrm{~A}$ unifying explanation for this coincidence would be that genetic compounds leading to higher FSH levels are more common in North European than in Far East regions.

To investigate these suggested mechanisms we propose that several studies should be carried out. No data are currently available on the secretion of gonadotropins in familial male dizygotic twins. We need to demonstrate that FSH levels are indeed higher in male dizygotic twins as well as in males whose mothers had dizygotic twins. Obviously it is important to evaluate the incidence of testicular carcinoma in males who have prolonged periods of el evated serum FSH levels. This is the case in males with only one testicle and in many males with dysfunctioning Sertoli/Leydig cells resulting in reduced hormonal negative feedback towards the pituitary gland.
Hopefully, in the near future, the gene(s) that underlie altered regulation of $\mathrm{FSH}$ secretion in twinning will be identified. These will then serve as prime candidate genes in sib-pair studies of testicular carcinoma.

The findings by Swerdlow and colleagues emphasise the clinical importance of research into the etiology of dizygotic twinning and demonstrate the great value of epidemiologic studies with twins in cancer research. In particular, the 35-fold increased risk in monozygotic twin sisters of patients with breast cancer and the 38 to 75-fold increase in twin brothers of patients with testicular cancer merit immediate clinical attention.

\section{References}

1 Swerdlow AJ, Stavola BL, Swanwick MA, Maconochie NES. Risk of breast and testicular cancers in young adult twins in England and Wales: evidence on prenatal and genetic aetiology. Lancet 1997; 350: 1723-1728.

2 Westergaard T, Olsen $\mathrm{H}$, Frisch $\mathrm{M}$, Kroman $\mathrm{N}$, Nielsen $\mathrm{W}$, Melbye M. Cancer risk in fathers and brothers of testicular cancer patients in Denmark. A population based study. Int $J$ Cancer 1996; 66: 627-631.

3 Martin NG, El Beaini J, Olsen ME, Bhatnagar AS, Macourt N. Gonadotropin levels in mothers who have had two sets of DZ twins. Acta Genet Med Gemellol 1984; 33: 131-139.

4 Lambalk CB, Boomsma DI, de Boer L, de Koning CH, Schoute E, Popp-Snijders C, Schoemaker J. Increased levels and pulsatility of Follicle Stimulating Hormone in mothers of heriditary dizygotic twins. J Clin Endocrinol Metab 1998; 83: 481-486.

5 Martin NG, Shanley S, Butt K, Osborne J, O'Brien G. Excessive follicular recruitment and growth in mothers of spontaneous dizygotic twins. Acta Genet Med Gemellol 1991; 40: 291-301.

6 Gilfillan CP, Robertson DM, Burger HG, Leoni MA, Hurley VA, Martin NG. The control of ovulation in mothers of dizygotic twins. JClin Endocrinol Metab 1996; 81: 1557-1562.

7 Meulemans WJ, Lewis CM, Boomsma DI, Derom CA, Van Den Berghe $\mathrm{H}$, Orlebeke $\mathrm{F}$, Vlietinck RF, Derom RM. Genetic modelling of dizygotic twinning in pedigrees of spontaneous dizygotic twins. Am J Med Genet 1996; 61: 258-263.

8 Sicinksy P, Donaher J, Geng Y, Parker SB, Gardner H, Park MY, Robker RL, Richards JS, McGinnis LK, Biggers JD, Eppig $\mathrm{J}$, Bronson RT, Elledge SJ, Weinberg RA. Cyclin D2 is an FSHresponsive gene involved in gonadal cell proliferation and oncogenesis. Nature 1996; 384: 470-474.

9 Satge D, Sasco AJ, Cure H, Leduc B, Sommelet D, Vekemans MJ. An excess of testicular germ cell tumours in Down's Syndrome. Cancer 1997; 80: 929-935.

10 Diamond IM. Variation in human testis size. Nature 1986; 320 : 488-489.

11 Smith PG. Comparison between registries: age-standardized rates. In: Parkin DM, Muir CS, Whelan SL, Gao Y-T, Ferlay J, Powell J (eds). Cancer Incidence in Five Continents. IARC Scientific Publications: Lyon, 1992, No 120, pp 972-973. 